Reorganization of Health Services and the N.H.S. Number

SIR,-At a time of reorganization of the National Health Services it would seem expedient to examine the benefits of restructuring the N.H.S. number. That number provides unique and permanent identification of all individuals in the country, and increasing use is being made of it in medical record linkage. ${ }^{1}$ However, it is exceptionally cumbersome to use because of its length and the variability of its format. ${ }^{2}$ Individuals seldom know their own numbers, and the space for the N.H.S. number on many medical documents is frequently left blank. ${ }^{1}$ For example, in cancer registrat:on in South Wales fewer than $4 \%$ of N.H.S. numbers are entered by hospitals at time of registration, and some of the entries are of their national insurance number.

One possible number that would be easier to remember and hence easier to use is suggested. It is a nine-digit alphanumeric in which the first two digits denote the year of birth and the second two are letters indicating the (new) health district of birth. Then follows a four-digit sequence allocated in turn to live births in the district in the year, and the number is terminated by a check digit. ${ }^{3}$ For example, a child born in Cardiff in early 1973 might be allocated the number 73CF00798, the 8 being the check digit. Identification of sex could also be incorporated by al'ocating only even numbers to boys or al'ernatively by allocating the first 4,999 numbers to boys.

The use of fixed-length format would overcome the difficulties of remembering and transcribing which are experienced with the present series of numbers. Inclusion of two alphabetic characters in fixed positions may aid comprehension and memorability of the whole number provided that the letters have easily identifiab'e significance. The proposed health districts have populations of approxiately 200,000 to $500,000^{4}$ and 676 two-letter combinations would allow description of the majority of districts by recognizable abbreviations (for example, CF for Cardiff). Code letters could be used also for immigrants indicating country of bir'h, and spare codes would be kept for "unplaced" births and for new or growing districts. The number of a person living to over 100 years would need to be flagged by the issuing authority to prevent reissue of the same number. National numbering systems similar to the one outlined have been introduced recently in Denmark, Norway, and Sweden..$^{5}$ In the Danish 10-digit number the leading six digits record the date of birth in day, month, and year but the district of birth is not identified.

In April 1974 the health services in England and Wales are to start afresh, in a reorganized form. Is this not a good opportunity to introduce a more easily useable N.H.S. number based on a simpler, fixedlength format? The same number could be adopted for national insurance purposes, and each person could be issued with a plastic cand bearing this new number. If it was possible to attach unique numbers to all persons in the country at short notice in 1939, it should also be possible to renumber those already registered.-I am, etc.,

ROBERT R. WEST Debartment of Social and Occupational Medicine, Department of Social and Occupation
Welsh National School of Medicine,
Cardiff

1 Acheson, E. D., Medical Record Linkage. London, Oxford University Press, 1967

fournal of $\mathrm{D}_{\text {Preventive }}$ T., and Cross, $\mathrm{K}_{\text {. W }} \mathrm{W}_{\text {., British }}$ fournal of

Post Office Report No 170 The Function Mathematics of Check 170. The

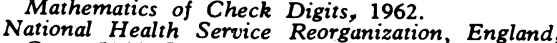
Cmn. 5055, London, H.M.S.O.. 1972.

Nielsen, H., in Record Linkage in Medicine

E. D. Acheson. Edinburgh, Livingstone, 1968 .

7 Donald, K. W., Lancet, 1949, 2, 1056.

Flenley, D. C., Cooke, N. J., King, A. J., Leitch,
A. G., and Brash, H. Mullin de PhysioA. G., and Brash, H. M., Bulleti pathologie Respiratoire, 1973, 9. 689 . de PhysioCampbell, E. J. M., British Medical fournal, 1965 , 1,1451 .

Hum, , R., British fournal of Haematology, 1968,
151.

\title{
Cancer and the Patient
}

\section{Oxygen Therapy in Chronic} Respiratory Failure

SIR,-We were interested to read the paper by Dr. R. Hume and others (20 October, p. 154). However, we feel that their postulate concerning tolerance of the respiratory centre to hypoxia in these patients needs to be challenged.

Firstly, the idea that a change in the "central oxygen state" regulates respiration is difficult to accept, as the only described effect of hypoxia on the respiratory centre is one of depression. ${ }^{1}$ The hypoxic drive is mediated by the peripheral chemoreceptors. ${ }^{2}$ Further, there was no mention of the altered response to $\mathrm{CO}_{2}$ in these patients, which is probably the most important factor determining "oxygen tolerance." In this connexion, we should like to draw attention to work from this department. ${ }^{34}$ This demonstrated that the mean ventilatory responses to $\mathrm{CO}_{2}$ was greatly reduced in patients with chronic respiratory failure. Add to this that these patients have a greatly diminished ventilatory capacity ${ }^{5}$ and it becomes clear, as was pointed out by Donald, ${ }^{6}$ that these patients are dependent on an intact hypoxic drive to maintain ventilation. With regard to the individual variation in the tolerance to oxygen of these patients, this was shown to exist and was measured in terms of the hypoxic potentiation of the $\mathrm{CO}_{2}$ response. ${ }^{3}$ However, the variation was no greater than in normals, ${ }^{3}$ a fact confirmed in a much larger series more recently. ${ }^{7}$ This is an interesting finding and may have practical implications, as discussed, but suggests very strongly that the individual variation in the patients with cor pulmonale can have little to do with the "level of arterial oxygen to which [the] respiratory centre has become accustomed during the quiescent phase of the disease."

Secondly, the authors seem to use Campbell's ${ }^{8}$ criteria to define hypercapnic chronic respiratory failure. If this is so, then it appears that 15 of the 30 patients studied failed to meet these criteria as their $\mathrm{PaO}_{2}$, as shown in the authors' figure, was greater than $60 \mathrm{~mm} \mathrm{Hg}$. Unfortunately, the $\mathrm{PaCO}_{2}$ values for all this group are not quoted but of the 15 which are given elsewhere only six were greater than $49 \mathrm{~mm} \mathrm{Hg}$.

What we also note is that $24 \%$ oxygen given empirically would have been safe and appropriate for all the patients reported who can be seen to have had hypercapnic respiratory failure.-We are, etc.,

L. J. Clancy

Department of Medicine,

A. G. LEITCH

Royal Infirmary,

Edinburgh

1 Kronenberg, R., et al., Respiration Physiology, 1972, 16, 109.' F., and Heymans, C., Archives
Heymans, J.
Internationales de Pharmacodynamie, 1926, 32, 9.

Flenley, D. C., and Millar, J. S., Clinical Science, Flenley D. C., Franklin, D. H., and Millar, J. Flenley, D. CC, and Millar, J. S., Clinical Science,
1968, 34, 385.
SIR,-When the diagnosis of cancer is made the problem arises whether or not the patient should be told (Mr. Charles Wright, 6 October, p. 45) and much of the recent correspondence on this subject in your columns has concerned the fear the diagnosis engenders in the patient. Two elements of this fear are the fear of death its If and the fear of a pain-racked, drugdoped terminal phase (Professor G. W. Milton, 27 October, p. 221). This latter is possibly the worse fear both from the patient's personal point of view and from the great, sometimes intolerable, strain the terminal period will place on the patient's immediate family.

In all the discussion no mention has been made of the place of induced hyperthermia in the management of the problem. The most striking effect of induced hyperthermia is the relief of the pain due to tumour invasion, which is relieved or abolished by one or two episodes of hyperthermia, and this is unrelated to the heat sensitivity of the particular malignancy (pain due to bony compression of nerve roots is unaffected). This pain relief often lasts for several weeks without further hyperthermia. A safe and reliable method of raising the body temperature is now availablel and a number of patients have been treated. After treatment the patient is alert and has a sense of well-being unrelated to the pain relief. This is in contrast to some of the after-effects of radiotherapy and antimitotic agents. While a single treatment with induced hyperthermia undoubtedly takes longer and requires more skilled attention than an injection of morphine, the patient after hyperthermia is able to continue a normal life, meeting people and getting out and about. This is not only of benefit to the patient, but the family also suffers less. If this therapy was more widely known and available some of the fear of cancer might be removed.-I am, etc.,

Department of Anaesthetics,

E. L. LLOYD Royal Infirmary, Edinburgh

Henderson, M. A., And
Lancet $_{\text {1971, 1, }}$ and

\section{Dermographia and Tattooing}

SIR,-We have been studying the incidence of dermographia in allergic and non-allergic subjects using the procedure described by Grolnick.1 In the course of this study an interesting observation was that on stroking a tattooed area of skin of a subject without dermographia, while no wealing occurred over the non-tattooed areas of the skin the tattooed skin showed wealing. In subjects with dermographia the wealing reaction was greater over the tattoo marks than over the non-tattooed skin. We would be interested to know if this has been observed by other workers interested in this subject. 
Further studies are being undertaken to certainly represented no clinical hazard. examine the histology of the tattooed skin to see if that would throw light on the reason behind the peculiar response of the tattooed skin.-We are, etc.,

K. V. THIRUVENGADAM

K. HARANATH

T. S. SEKAR

Government Stanley Hospital, K. R. RAJAGOPAL

Madras

1 Grolnick, M., Annals of Allergy, 1970, 28, 395.

\section{Multiple Sclerosis among Immigrants}

SIR,-With the co-operation of the Multiple Sclerosis Society of Great Britain and Northern Ireland I am undertaking a study of the prevalence of multiple sclerosis (M.S.) among immigrants to England both from areas of the world where the disease is common, such as Ireland and Europe, and from areas of the world where the prevalence is thought to be low-Africa, Asia, and the West Indies. If immigrants from lowprevalence countries are immune to M.S. they should keep their low risk; if on the other hand they are not immune they should have a greatly increased risk of developing M.S. on immigrating to England. Most of the immigrants from low-prevalence areas have settled in Greater London and the Central Midlands and in these areas, with the permission of the research committees of the hospitals, over 9,000 M.S. case-folders have now been studied in order to ascertain the birthplace of the patients. This study has proved to be very successful, but some immigrants from low-prevalence countries have no doubt been missed.

I am very anxious to ask doctors who know of any M.S. patient who was born in a low-prevalence part of the world if they would co-operate with this study by informing me about the patient, with the patient's permission. I am, etc.,

Medico-Social Research Board,

GEOFFREY DEAN 73 Lower Baggot Street,

Dublin 2

\section{Suicidal Attempts with Beta-adrenoceptor Blocking Agents}

SIR,-Drs. P. Karhunen and G. Härtel (21 April, p. 178) reported a case of attempted suicide with $9,000 \mathrm{mg}$ of practolol. Apart from very modest reductions in blood pressure and heart rate, no effects were observed and no special treatment was necessary. The highest measured plasma concentration of practolol was $58.6 \mu \mathrm{g} / \mathrm{ml}$. More recently Drs. W. Wermut and $M$. Wójcicki (15 September, p. 591) reported a case of attempted suicide with $2,000 \mathrm{mg}$ of propranolol. No signs of cardiac disturbance were observed after what is described as a "massive" dose of propranolol. The authors concluded that "the effect of propranolol on the healthy heart needs to be reconsidered."

We have recently reported ${ }^{1}$ the effects of beta-andrenoceptor blocking agents in healthy human volunteers. Maximally tolerated doses were administered intravenously over five minutes. These were: practolol $1,280 \mathrm{mg}$, propranolol $120 \mathrm{mg}$, oxprenolol $160 \mathrm{mg}$, sotalol $160 \mathrm{mg}$, and pindolol $16 \mathrm{mg}$. Effects on supine blood pressure and heart rate were slight and
There was, of course, marked antagonism of any induced increase in heart rate. Plasma on the basis of the work of Aellig et al..$^{2}$ it is estimated that the peak plasma level of practolol in our lightest subject $(62 \mathrm{~kg})$ was approximately $100 \mu \mathrm{g} / \mathrm{ml}$

Doses of beta-adrenoceptor blocking agents required to achieve therapeutic effect cover a wide range. Zacharias and Cowen ${ }^{3}$ found that more than $15 \%$ of hypertensive patients required $1,000 \mathrm{mg}$ or more of propranolol daily. Kincaid-Smith et al. ${ }^{4}$ report using propranolol in doses up to $2,000 \mathrm{mg}$ daily and Prichard $^{5}$ up to $4,000 \mathrm{mg}$ daily. Of course these doses have been achieved after gradual titration, and it is appreciated that in patients with incipient cardiac failure it is the starting dose that is likely to precipitate overt failure. However, even this hazard might well be prevented by prior digitalization.

When maintenance of resting cardiac output. relies on sympathetic drive, administration of a beta-adrenoceptor blocking agent might, by antagonizing that drive, precipitate cardiac failure. The healthy subject when resting supine maintains cardiac output and blood pressure in the absence of sympathetic drive, and so in this situation beta-adrenoceptor blocking agents, even in "massive" dosage, are not likely to represent a hazard.-We are, etc.,

Charing Cros

A. J. BOAKES

Roydon, Essex

B. H. BOEREE

1 Boakes, A. J., Boeree, B. H., and Prichard B.N.C., Naunyn-Schmiedebergs Archiv für experimentelle Pathologie und Pharmakologie, Aellig, W. H., Prichard, B. N. C., and Scales, B., British fournal of Pharmacology, 1970, 40, 573P.

3 Zacharias, F. J., and Cowen, K. J., British Medical Fournal, 1970, 1, 471.

Kincaid-Smith, P. Fang, P., and Laver, M. C., Clinical 5 Prichard, B. N. C., British fournal of Hospital
Medicine, 1973, 10, 45.

\section{Depression of Cellular Immunity in \\ Pregnancy due to a Serum Factor}

SIR,-The article by Dr. C. A. St. Hill and others (8 September, p. 513) is a wonderful example of how to hoodwink a venerable journal with statistical " $t$ "s and " $P$ "s, even when wrongly applied and irrelevantly theorized.

Consider that the $t$ test was used to compare, within the same experiment, five groups of data: $(A+B)$ with $(C+D),(C)$ with (D), and $(A+B+C+D)$ with (E). The correct method of analysis here would be analysis of variance, and I would guess that if anything were significant in the experiment by analysis of variance, only the last grouping might be. Of course, we don't even know how good the technique is, since the authors don't give us their normal values of lymphocytes in autologous serum with standard deviations thereof-it might discourage us from pursuing the paper.

Finally, to add insult to injury, the theorization is done not on the allegedly significant differences, but those which are insignificant (namely, (C) against (D), or "fetal serum has a greater depressive action than maternal serum").
Please, if we are to have statistics, let them be correctly planned, expertly presented, and judiciously edited.-I am, etc.,

A. M. MUNSTER

Department of Surgery

Medical University of South Carolina,

${ }^{*}{ }^{*}$ We showed Mr. Munster's letter to Dr. St. Hill and his colleagues, whose reply is printed below.-ED., B.M.f.

SIR,-If there had been no prior reason for testing the difference between the pregnant $(C+D)$ and non-pregnant $(A+B)$ sera, the significant result $(\mathrm{P}<0.01)$ might have been dismissed as an effect of multiple comparisons, but the investigation was concerned with a difference of this kind. To report an analysis of variance, as a process of unguided statistical exploration, would have been superfluous. Moreover, the most important of the possible comparisons, that of (E) with $(A+B+C+D)$ is too highly significant to be dismissed in this way. The choice of the comparative transformation rate for the statistical analysis is an orthodox use of standard statistical techniques.

Mr. Munster is guilty of quoting out of context. Our statement that "fetal serum has a greater depressive action than maternal serum" was heavily qualified. Thus it was immediately preceded by the phrase: "Our results raise the possibility that ....," and in the results section we noted that the difference in the suppressive action of fetal and maternal serum was statistically not significant. We therefore thought that we had made it sufficiently clear that this was only a suggestion; moreover, it only constitutes an unimportant part of our thesis.

Some years ago an eminent professor of orthopaedics who was opposed to, and probably ignorant of, the value of statistical analysis used to teach his students that statistics were not essential and that "if it's important, laddie, it will hit you in the eye." The kernel of our paper was the difference shown in the figure between $(A+B+C+D)$ and (E). This surely "hits one in the eye," and statistical wrangling, however elegant, cannot possibly obscure this observation. -We are, etc.,

C. A. ST. Hill R. FINN

Pathology Department,

Royal Southern Hospital,
Liverpool

\section{Making Hospital Geriatrics Work}

SIR,-May I reply to Dr. R. V. Boyd (3 November, p. 298), who comments on the paper by Dr. P. M. Jefferys and myself (2 December 1972, p. 536)?

Dr. Boyd found that an $11 \%$ bed reduction suddenly imposed on his active department at Greenwich resulted in a catastrophic fall in admission rate and the accumulation of a large waiting list. One sympathizes with him on this unfortunate occurrence, but he does indicate that there were some unusual circumstances. In his well-bedded days he took on "a high long-stay commitment to help out other agencies under stress." In contrast to the . Greenwich experience, other active departments have found it possible effectively to reduce their 